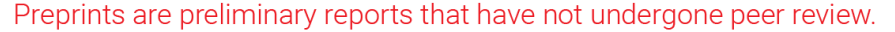 They should not be considered conclusive, used to inform clinical practice, or referenced by the media as validated information. \\ Correlations between gender, age and the risk of withdrawal from peritoneal dialysis
}

\author{
Min Yan Zhang \\ Wuhan NO·1 Hospital \\ Miao He (D834148183@qq.com ) \\ Wuhan No1 Hospital https://orcid.org/0000-0002-4006-9016 \\ Sheng Wan \\ Wuhan NO· 1 Hospital \\ Qiong Yan Ding \\ Wuhan NO· 1 Hospital \\ Lei Liu \\ Wuhan University of Bioengineering

\section{Fei Xiong} \\ Wuhan NO·1Hospital \\ Lin Yang $\mathrm{Hu}$ \\ Wuhan NO· 1 Hospital
}

\section{Research article}

Keywords: Peritoneal Dialysis,Technique Survival, Age, Sex, Cox Proportional Hazards Model

Posted Date: May 8th, 2020

DOI: https://doi.org/10.21203/rs.3.rs-25404/v1

License: (c) (1) This work is licensed under a Creative Commons Attribution 4.0 International License.

Read Full License 


\section{Abstract}

Background With the increasing incidence of end stage renal disease(ESRD),peritoneal dialysis(PD) has become the preferred method of kidney replacement therapy for an increasing number of patients with end stage renal disease due to its many advantages. The intent of this study was to explore the correlations between sex, age and risk of withdrawal from peritoneal dialysis.

Methods All patients who underwent PD catheterization and initiated PD at Wuhan No.1 Hospital between 2013 and 2018 were screened.Clinical information of these patients was collected and compared according to gender and age,then was applied to the Cox proportional hazards model to determine the impact of factors of withdrawal from peritoneal dialysis.

Results $\otimes$ Hazard ratios(HRs) of withdrawal of PD associate with gender and age at initiation were $0.736(P=0.289) \varangle 1.151 \square P=0.489$ respectively. Nonetheless, male patients under 60 years old had a 1.58fold higher risk of withdrawal than others $(H R 0.63, P=0.031) . \otimes T h e$ withdrawal risk of patients with total Creatinine clearance rate $(\mathrm{Ccr})$ above $60 \mathrm{~L} / \mathrm{W}$ was $82.4 \%$ higher than that of patients who did not meet the standard (HR 1.82,P $=0.005)$. $邓$ The withdrawal risk of patients with high D/P Creatinine $[\mathrm{Cr} \square$ value which was calculated from peritoneal equilibration test(PET) were 2.06 times higher than low-average and highaverage transport patients(HR2.06, $P=0.008)$. खPatients with serum albumin above $35 \mathrm{~g} / \mathrm{L}$ were intended to withdraw from PD than those below $35 \mathrm{~g} / \mathrm{L}(\mathrm{HR} 0.56, \mathrm{P}=0.006)$.

Conclusions There were significant differences in total KT/V, total Ccr,serum creatinine(Scr) and blood Urea nitrogen(BUN)among patients with PD of different gender and age. The analysis showed that male patients under 60 years old, Ccr, value of D/Pcr and serum albumin had a high correlation with the technical survival rates. While gender or age at PD initiation were not associated with technique survival,male patients under 60 years old had a 1.58-fold higher risk of withdrawal from PD than others. The outcome that the withdrawal risk of patients with Ccr above $60 \mathrm{~L} / \mathrm{W}$ was $82.4 \%$ higher than other patients who did not meet the standard suggested that Ccr was not suitable as an index for evaluating the adequacy of PD,especially for men under 60 years old.And patients with high D/Pcr value or with serum albumin under $35 \mathrm{~g} / \mathrm{L}$ were related risk factors for technique survival.

\section{Background}

Epidemiological data showes that the prevalence of chronic kidney disease (CKD) worldwide is 8-16\% ${ }^{[1]}$

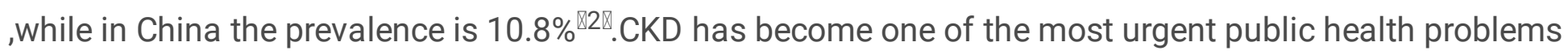
that needs to be solved all over the world due to its long course of disease,diverse etiology and complicated treatment.Subsequently,the incidence of ESRD has increased obviously with the increasing rate of CKD.Thus,peritoneal dialysis, which has the advantages of lower price, simpler equipment,more convenient operation,smaller impacts on hemodynamics,lower cross-infection rate,less impacts on work and life,and more favorable for the protection of residual renal function ${ }^{\llbracket 3 \rrbracket}$ compared with hemodialysis(HD),has become the preferred renal replacement therapy for more and more patients with 
ESRD.Here,we aimed to explore the different characteristics of gender and age in some indicators of peritoneal dialysis, as well as the risk factors of technique survival,in order to find relevant strategies to further improve the survival rate of peritoneal dialysis.

\section{Methods}

\section{Patients and study design}

A total of 380 patients with ESRD who underwent surgical PD catheter placement and started continuous ambulatory peritoneal dialysis(CAPD) treatments more than 3 months at the peritoneal dialysis center of Wuhan No.1 Hospital from January 1, 2013 to December 31, 2018 were analyzed retrospectively.Forty three patients were excluded due to age below 18 years old at PD initiation,PD duration less than 3 months or missing data.Finally,337 patients were identified and included in the study. Among them, 167 were males (49.55\%). The mean age of patients at the start of CAPD was $53.55 \pm 13.70$ years old. Except for gender and age,other clinical information regarding time of starting CAPD, numbers of dialysate bags, primary diseases and so on were collected.As it was showed in table 1,there was no statistically significant difference in age at PD initiation or numbers of dialysate bags,but PD duration of male patients was less than that of female patients and male patients had a higher proportion of complication of diabetes mellitus(DM) than females.

Table 1 Comparison of Patients' Basic Information by Gender Group

\begin{tabular}{llll} 
Baseline & Male $(\mathrm{N}=167)$ & Female $(\mathrm{N}=170)$ & P-value \\
\hline${ }^{\text {a Age at PD initiation(years) }}$ & $52.89 \pm 13.76$ & $54.21 \pm 13.66$ & 0.541 \\
\hline bPD duration(months) & $23.00(13.00,39.00)$ & $29.00(16.00,46.25)$ & $0.037^{\star}$ \\
\hline cDiabetes mellitus & $20.36 \%$ & $11.76 \%$ & $0.032^{\star}$ \\
\hline b Numbers of dialysate bags(bags) & $4.00(4.00,4.00)$ & $4.00(3.00,4.00)$ & 0.149
\end{tabular}

Datas were presented as mean $\pm S D$ or median;a.Unpaired t-test is used for normally distributed datas;b.Non-parametric test is adopted for datas do not conform to normal distribution;c.Chi-square test is used for categorical datas.; ${ }^{*} P$-value $<0.05, \triangle P$-value $<0.01$; The following was still applicable if not marked.

\section{Data collection}

The peritoneal equilibration test ${ }^{[5]}$ was carried according to the standard operating procedures of peritoneal dialysis (2010), dialysis fluid and blood samples were collected at $0 \mathrm{~h}, 2 \mathrm{~h}$ and $4 \mathrm{~h}$ respectively after peritoneal retention, and D/P Cr value was calculated by using the ratio of creatinine of Peritoneal dialysate to serum creatinine.Indexes related to dialysis and biochemical examination were measured by automatic analyzer in our hospital,including hemoglobin,serum albumin,electrolytes, urea nitrogen and 
creatinine,then calculating ${ }^{[5]}$ total creatinine clearance $(\mathrm{Ccr})$ and total urea clearance index (KT/V) per week.

\section{Statistical analyses}

Statistical analyses was performed using SPSS version

24.0(SPSSInc,Chicago,IL,USA)software.Categorical data were described as proportions.Quantitative data were reported as the mean \pm standard deviation (SD)(datas conforming to the normal distribution) or as median or quartiles, as appropriate.For comparison between two groups, Independent-Samples $\mathrm{T}$ test was used for data conforming to normal distribution, otherwise Mann-Whitney Test was used.As for comparison among multiple groups, Analysis of Variance was used for datas which met the normal distribution and homogeneity of variance;or else Nonparametric Test was used.In pairwise comparison among multiple groups, BonferroriTest was used for data of homogeneity of variance, and Nonparametric

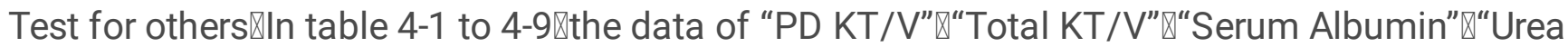

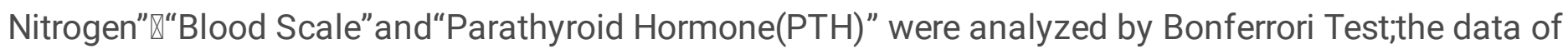
"residual kidney Ccr" $₫$ "total Ccr"and "serum creatinine"were analyzed by Nonparametric Test $\gtrsim$.Death,kidney transplant or transferring to HD was used as the end point for the analysis of patient when analyzing technique survival. The risk factors for technique survival was analyzed with a multivariate Cox's proportional-hazard model in which we included all the significant variables from the univariate analysis and variables which were considered clinically relevant according to the current literature. Differences were considered statistically significant for $P$ values less than 0.05 .

\section{Results}

Of the 337 CAPD patients in the study, 167 (49.55\%) were males. The mean age at the start of PD was $53.55 \pm 13.70$ years old. Chronic glomerulonephritis was the most common cause of ESRD (45.99\%), followed by diabetes mellitus (16.02\%), hypertension (15.13\%),obstructive nephropathy (5.64\%), systemic lupus erythematosus (3.56\%), and other causes. By the end of event, 30(8.9\%) patients died,11 (3.2\%) patients received renal transplantation,59 (17.4\%) patients switched to hemodialysis $₫ 237$ (70.3\%) patients continued undergoing PD.

\section{Patients outcomes}

Comparing the differences of indicators in patients with peritoneal dialysis by gender $\Downarrow$ we could learn from table 2 that the data of male patients were higher than that of female patients in residual renal Ccr, peritoneal Ccr, total creatinine clearance rate, $\mathrm{D} / \mathrm{P} \mathrm{Cr}$, urea nitrogen and blood creatinine. However, female patients had advantages over male patients in the aspect of peritoneal dialysis KT/V, total KT/V and serum calcium.

Table 2 Comparison of different genders in various indicators 


\begin{tabular}{|c|c|c|c|c|}
\hline Indicator & Male(N = 167) & Female $(\mathrm{N}=170)$ & $T / Z$ & $\mathrm{P}$ \\
\hline${ }^{\mathrm{b}} \mathrm{KT} / \mathrm{V}$ of residual kidney & $0.20(0.00,0.48)$ & $0.23(0.00,0.57)$ & 0.243 & 0.808 \\
\hline${ }^{\mathrm{a}} \mathrm{KT} / \mathrm{V}$ of $\mathrm{PD}$ & $1.21+/-0.34$ & $1.77+/-0.41$ & 13.468 & $0.000^{\triangle}$ \\
\hline${ }^{\mathrm{b}}$ Total KT/V & $1.47(1.29,1.72)$ & $2.12(1.73,2.40)$ & 9.911 & $0.000^{\triangle}$ \\
\hline${ }^{\mathrm{b}} \mathrm{Ccr}$ of residual kidney(L/W) & $13.15(0.00,31.82)$ & $9.24(0.00,21.18)$ & 2.502 & $0.012^{*}$ \\
\hline${ }^{\mathrm{b}} \mathrm{Ccr}$ of $\mathrm{PD}(\mathrm{L} / \mathrm{W})$ & $45.65(37.88,51.28)$ & $41.47(35.01,48.00)$ & 2.894 & $0.004^{\triangle}$ \\
\hline${ }^{\mathrm{b}}$ Total $\operatorname{Ccr}(\mathrm{L} / \mathrm{W})$ & $58.49(50.30,75.06)$ & $51.86(44.32,64.48)$ & 4.195 & $0.000^{\triangle}$ \\
\hline${ }^{\mathrm{b}} \mathrm{PET}$ (D/P value) & $0.67(0.57,0.75)$ & $0.61(0.57,0.69)$ & 2.152 & $0.031^{*}$ \\
\hline${ }^{\mathrm{a}} \mathrm{Hb}(\mathrm{g} / \mathrm{L})$ & $102.99+/-19.03$ & $101.71+/-19.12$ & 0.614 & 0.540 \\
\hline bSerum albumin $(\mathrm{g} / \mathrm{L})$ & $35.60(32.70,38.80)$ & $35.70(32.30,38.80)$ & 0.546 & 0.585 \\
\hline${ }^{\mathrm{b}} \mathrm{BUN}(\mathrm{mmol} / \mathrm{L})$ & $18.00(14.30,21.90)$ & $15.95(12.48,20.03)$ & 3.252 & $0.001^{\triangle}$ \\
\hline${ }^{\mathrm{a} S c r}$ (mumol /L) & $991.26+$ / - 338.08 & $824.56+/-221.92$ & 5.341 & $0.000^{\triangle}$ \\
\hline bSerum kalium (mmol/L) & $4.00(3.50,4.50)$ & $4.10(3.60,4.60)$ & 0.594 & 0.552 \\
\hline${ }^{a}$ Serum calcium (mmol/L) & $2.20+/-0.24$ & $2.26+/-0.24$ & 2.538 & $0.012^{*}$ \\
\hline $\begin{array}{l}\text { aserum phosphate } \\
(\mathrm{mmol} / \mathrm{L})\end{array}$ & $1.56+/-0.51$ & $1.53+/-0.48$ & 0.530 & 0.596 \\
\hline${ }^{\mathrm{b}}$ Serum ferritin (mug /L) & $202.10(103.80,362.40)$ & $182.20(89.50,349.58)$ & 0.959 & 0.338 \\
\hline bPTH (pg/ml) & $222.60(117.10,440.20)$ & $291.95(118.03,518.53)$ & 1.512 & 0.130 \\
\hline
\end{tabular}

Subsequently, divided all the patients into four groups to estimate the differences of each group in various indicators. Group A included male patients whose age were less than 60 years old(109 cases),group B included female patients whose age were under 60 years old (102 cases),group $C$ included male patients whose age were more than 60 years old(58 cases),group D included female patients whose age were more than 60 years old(68 cases), respectively.

Table 3 Comparison of four groups of $A B C D$ in each indicator 
Project

Group A Group B Group C

Group $\quad F$

D

\begin{tabular}{|c|c|c|c|c|c|c|}
\hline $\begin{array}{l}\mathrm{e}_{\mathrm{KTT}} / \mathrm{V} \text { of residual } \\
\text { kidney }\end{array}$ & 0.20 & 0.24 & 0.21 & 0.21 & 0.164 & 0.920 \\
\hline${ }^{d} K T / V$ of $P D$ & $1.20 \pm 0.33$ & $1.83 \pm 0.40$ & $1.24 \pm 0.36$ & $\begin{array}{l}1.68 \pm \\
0.42\end{array}$ & 63.354 & $0.000^{\triangle}$ \\
\hline${ }^{\mathrm{e}}$ Total KT/V & 1.48 & 2.19 & 1.45 & 2.05 & 34.340 & $0.000^{\triangle}$ \\
\hline $\begin{array}{l}{ }^{\mathrm{e}} \mathrm{Ccr} \text { of residual } \\
\text { kidney }(\mathrm{L} / \mathrm{W})\end{array}$ & 13.74 & 9.24 & 12.42 & 9.29 & 3.528 & $0.016^{*}$ \\
\hline${ }^{e} \mathrm{Ccr}$ of $\mathrm{PD}(\mathrm{L} / \mathrm{W})$ & 46.10 & 42.14 & 44.11 & 40.12 & 2.478 & 0.061 \\
\hline${ }^{\mathrm{e}}$ Total Ccr (L/W) & 59.54 & 52.19 & 55.71 & 50.24 & 5.724 & $0.001^{\triangle}$ \\
\hline ePET(D/P value) & 0.66 & 0.62 & 0.67 & 0.61 & 2.090 & 0.104 \\
\hline${ }^{\mathrm{e}} \mathrm{Hb}(\mathrm{g} / \mathrm{L})$ & 105.00 & 102.00 & 98.50 & 100.50 & 0.710 & 0.547 \\
\hline $\begin{array}{l}\text { eSerum albumin } \\
(\mathrm{g} / \mathrm{L})\end{array}$ & 37.20 & 36.20 & 34.50 & 34.50 & 4.896 & $0.002^{\triangle}$ \\
\hline $\begin{array}{l}\text { e } \mathrm{BUN}(\mathrm{mmol} / \mathrm{L}) \\
(\mathrm{mmol} / \mathrm{L})\end{array}$ & $19.27 \pm 5.98$ & $16.80 \pm 5.51$ & $16.96 \pm 5.40$ & $\begin{array}{l}15.49 \\
\pm 5.44\end{array}$ & 7.095 & $0.000^{\triangle}$ \\
\hline${ }^{\mathrm{e}} \mathrm{Scr}$ (mumol /L) & $\begin{array}{l}1048.56 \\
\pm 338.96\end{array}$ & $\begin{array}{l}887.38 \pm \\
207.13\end{array}$ & $883.57 \pm 311.60$ & $\begin{array}{l}730.34 \\
\pm \\
221.02\end{array}$ & 19.237 & $0.000^{\triangle}$ \\
\hline $\begin{array}{l}\text { eSerum } \\
\text { kalium(mmol/L) }\end{array}$ & 4.10 & 4.15 & 3.85 & 4.00 & 1.295 & 0.276 \\
\hline $\begin{array}{l}\text { dSerum calcium } \\
(\mathrm{mmol} / \mathrm{L})\end{array}$ & $2.19 \pm 0.24$ & $2.27 \pm 0.24$ & $2.21 \pm 0.23$ & $\begin{array}{l}2.25 \pm \\
0.23\end{array}$ & 2.297 & 0.077 \\
\hline $\begin{array}{l}\text { dSerum } \\
\text { phosphate(mmol/L) }\end{array}$ & $1.62 \pm 0.49$ & $1.64 \pm 0.48$ & $1.43 \pm 0.52$ & $\begin{array}{l}1.35 \\
\pm 0.43\end{array}$ & 6.963 & $0.000^{\triangle}$ \\
\hline $\begin{array}{l}\text { eserum ferritin (mug } \\
/ L \text { ) }\end{array}$ & 210.30 & 177.85 & 188.20 & 202.45 & 0.761 & 0.517 \\
\hline ePTH (pg/ml) & 278.70 & 319.00 & 193.60 & 212.95 & 2.860 & $0.037^{*}$ \\
\hline
\end{tabular}

d.Analysis of Variance is used for datas which meet the normal distribution and homogeneity of variance;e.Non-parametric test is adopted for datas do not conform to normal distribution or homogeneity of variance. 
As it showed in table 3,the indicators of peritoneal of $\mathrm{KT} / \mathrm{V}$,total $\mathrm{KT} / \mathrm{V}$, residual renal Ccr, total Ccr,serum albumin, urea nitrogen, blood creatinine,blood phosphorus and PTH had statistical differences. Thus, the above indicators were further compared and analyzed to obtain table 4-1 to 4-9. The data in the follow tables showed the average difference of any two groups of $A$ to $D$.

Table 4-1 Comparison of four groups in PD KT/V

\begin{tabular}{lllll}
$\mathrm{J}$ & Group A & Group B & Group C & Group D \\
$\mathrm{I}$ & & & & \\
\hline Group A & - & $0.629^{\triangle}$ & 0.047 & $0.484^{\triangle}$ \\
\hline Group B & $0.629^{\triangle}$ & - & $0.582^{\triangle}$ & 0.146 \\
\hline Group C & 0.048 & $0.582^{\triangle}$ & - & $0.436^{\triangle}$ \\
\hline Group D & $0.484^{\triangle}$ & 0.146 & $0.436 \triangle$ & -
\end{tabular}

Table 4-1 showed the data of PD KT/V of female patients was higher than that of male patients at any age.

Table 4-2 Comparison of four groups in total KT/V

\begin{tabular}{lllll}
$\mathrm{J}$ & Group A & Group B & Group C & Group D \\
$\mathrm{I}$ & & & & \\
\hline Group A & - & $0.592^{\triangle}$ & 0.036 & $0.489 \triangle$ \\
\hline Group B & $0.592^{\triangle}$ & - & $0.556^{\triangle}$ & 0.104 \\
\hline Group C & 0.036 & $0.556^{\triangle}$ & - & $0.452^{\triangle}$ \\
\hline Group D & $0.489 \triangle$ & 0.104 & $0.452^{\triangle}$ & -
\end{tabular}

As it showed in table 4-2, the data of total KT/V of female patients at any age was higher than that of male patients.

Table 4-3 Comparison of four groups in residual renal Ccr 


\begin{tabular}{lllll} 
J & Group A & Group B & Group C & Group D \\
I & & & & \\
\hline Group A & - & $11.485^{\star}$ & 2.312 & 9.490 \\
\hline Group B & $11.485^{*}$ & - & 9.173 & 1.995 \\
\hline Group C & 2.312 & 9.173 & - & 7.178 \\
\hline Group D & 9.490 & 1.995 & 7.178 & -
\end{tabular}

Table 4-3 showed that the residual renal Ccr of male patients under 60 years old was higher than that of female patients of the same age group.

Table 4-4 Comparison of four groups in total Ccr

\begin{tabular}{lllll}
$\mathrm{J}$ & Group A & Group B & Group C & Group D \\
$\mathrm{I}$ & & & & \\
\hline Group A & - & $13.881 \triangle$ & 4.516 & $14.609 \triangle$ \\
\hline Group B & $13.881 \triangle$ & - & 9.365 & 0.729 \\
\hline Group C & 4.516 & 9.365 & - & 10.094 \\
\hline Group D & $14.609 \triangle$ & 0.729 & 10.094 & -
\end{tabular}

Table 4-4 showed that the total creatinine clearance rate of male patients under 60 years old was higher than that of female patients at any age.

Table 4-5 Comparison of four groups in serum albumin

\begin{tabular}{lllll}
$\mathrm{J}$ & Group A & Group B & Group C & Group D \\
$\mathrm{I}$ & & & & \\
\hline Group A & - & 1.046 & $2.809^{\star}$ & 1.982 \\
\hline Group B & 1.046 & - & 1.763 & 0.935 \\
\hline Group C & $2.809^{\star}$ & 1.763 & - & 0.828 \\
\hline Group D & 1.982 & 0.935 & 0.828 & -
\end{tabular}

As it showed in table 4-5, the level of serum albumin of male patients under 60 years old was significantly higher than that of male patients over 60 years old.

Table 4-6 Comparison of four groups in blood urea nitrogen 


\begin{tabular}{lllll} 
J & Group A & Group B & Group C & Group D \\
I & & & & \\
\hline Group A & - & $2.467^{*}$ & 2.310 & $3.778^{\triangle}$ \\
\hline Group B & $2.467^{\star}$ & - & 0.156 & 1.311 \\
\hline Group C & 2.310 & 0.156 & - & 1.468 \\
\hline Group D & $3.77{ }^{\triangle}$ & 1.311 & 1.468 & -
\end{tabular}

Table 4-6 showed that the data of blood urea nitrogen in male patients under 60 years old was higher than that of female patients at any age.

Table 4-7 Comparison of four groups in serum creatinine

\begin{tabular}{lllll} 
J & Group A & Group B & Group C & Group D \\
I & & & & \\
\hline Group A & - & $161.177^{\triangle}$ & $164.991^{\star}$ & $318.224^{\triangle}$ \\
\hline Group B & $161.177^{\triangle}$ & - & 3.813 & $157.044^{\triangle}$ \\
\hline Group C & $164.991^{\star}$ & 3.813 & - & $153.231^{\star}$ \\
\hline Group D & $318.221^{\triangle}$ & $157.044^{\triangle}$ & $153.231^{\star}$ & -
\end{tabular}

Table 4-7 showed that the data of serum creatinine of male patients younger than 60 years old was higher than that of female patients at any age, as well as male patients older than 60 years old. While female patients younger than 60 years old had higher level of it than that of same-sex patients older than 60 years old. Nonetheless the data of serum creatinine of male patients older than 60 years old was significantly higher than that of female patients.

Table 4-8 Comparison of four groups in blood phosphorus

\begin{tabular}{lllll} 
J & Group A & Group B & Group C & Group D \\
I & & & & \\
\hline Group A & - & 0.024 & 0.186 & $0.269 \triangle$ \\
\hline Group B & 0.024 & - & 0.210 & $0.293^{\triangle}$ \\
\hline Group C & 0.186 & 0.210 & - & 0.083 \\
\hline Group D & $0.269 \triangle$ & $0.293^{\triangle}$ & 0.083 & -
\end{tabular}


It could be seen from table 4-8 that the level of blood phosphorus of male and female patients younger than 60 years old was higher than that of female patients older than 60 years old.

Table 4-9 Comparison of four groups in PTH

\begin{tabular}{lllll} 
J & Group A & Group B & Group C & Group D \\
I & & & & \\
\hline Group A & - & 63.590 & 82.573 & 38.652 \\
\hline Group B & 63.590 & - & $146.162^{*}$ & 102.242 \\
\hline Group C & 82.573 & $146.162^{*}$ & - & 43.920 \\
\hline Group D & 38.652 & 102.242 & 43.920 & -
\end{tabular}

Table 4-9 showed that the data of PTH of female patients younger than 60 years old was higher than that of male patients older than 60 years old.

Taking all of the above into account,we can draw conclusions as follows: $\ T$ The value of peritoneal dialysis $\mathrm{KT} / \mathrm{V}$ of female patients was significantly higher than that of male patients, as well as total KT/V,no

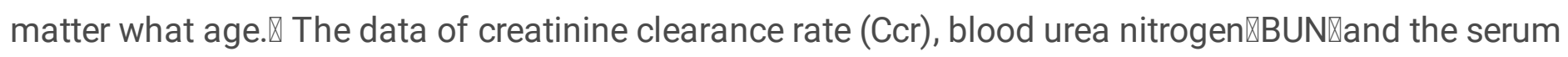
creatinine $\mathbb{S}$ crखof male patients under 60 years old was higher than that of female patients at any age. $\otimes$ The patients under 60 years old had higher level of Scr than that of same-sex people who was beyond 60 years old,while the data of Scr of male patients was higher than that of female in the sameage group. $\otimes T$ The P/D Cr value of female patients was lower than that of male patients.

These results indicated that there were differences in the biochemical indexes of patients divided into groups by gender and age,especially for those male patients younger than 60 years old.Therefore,what was the correlation between gender,age and the risk of exit from PD?Taking death,kidney transplant or transferring to hemodialysis as the end of event to analyze technique survival,gender,age at the beginning of dialysis,male patients with age less than 60 years old,primary disease,total KT/V,total creatinine clearance,PET,Hb,serum albumin,serum kalium,calcium,serum phosphate,serum ferritin,and PTH were taken as the independent variables (details in table 5).

Table 5 Assignment of risk factors for technique survival 
Factors

Assignment instructions

Age at PD initiation

$<60$ years $=0, \geq 60$ years $=1$

Gender

Male $=0$, female $=1$

PD duration

month

Male patients with

Yes $=0$, no $=1$

age under 60 years

old

Primary disease

Glomerulonephritis $=0$, hypertension $=1$, obstructive nephropathy $=2$, lupus $=3$, diabetes $=4$, others $=5$

Degree of education

Primary or middle school $=0$, high school $=1$, college or above $=2$, illiteracy $=3$

Region

Suburban $=0$, urban $=1$, other $=2$

Payment method

Urban employees' medical insurance $=0$, Urban residents' medical insurance $=1$, New cooperative medical scheme $=2$, Self-paying and others $=3$

Ending

Endpoint event $=0$, truncation $=1$

$\mathrm{KT} / \mathrm{V}$

$<1.7=0, \geq 1.7=1$

Total Ccr

$<60 \mathrm{~L} / \mathrm{W}=0, \geq 60 \mathrm{~L} / \mathrm{W}=1$

PET(D/Pvalue)

$0.5-0.81=0,0.3-0.49=1,0.82-1.03=2$

Scr

$\varangle 991.26 \mu \mathrm{mol} / \mathrm{L}=0, \geq 991.26 \mu \mathrm{mol} / \mathrm{L}=1$

BUN

$\nabla 18.00 \mathrm{mmol} / \mathrm{L}=0, \geq 18.00 \mathrm{mmol} / \mathrm{L}=1$

$\mathrm{Hb}$

$\nabla 100 \mathrm{~g} / \mathrm{L}=0, \geq 100 \mathrm{~g} / \mathrm{L}=1$

Serum albumin

$\varangle 35 \mathrm{~g} / \mathrm{L}=0, \geq 35 \mathrm{~g} / \mathrm{L}=1$

Serum kalium

$3.5-5.3 \mathrm{mmol} / \mathrm{L}=0 \otimes \square 3.5 \mathrm{mmol} / \mathrm{L}=1, \geq 5.3 \mathrm{mmol} / \mathrm{L}=2$

Serum calcium

$2.00-2.80 \mathrm{mmol} / \mathrm{L}=0 \otimes \otimes 2.00 \mathrm{mmol} / \mathrm{L}=1, \geq 2.80 \mathrm{mmol} / \mathrm{L}=2$

Serum phosphate

$0.80-1.50 \mathrm{mmol} / \mathrm{L}=0 \otimes \otimes 0.80 \mathrm{mmol} / \mathrm{L}=, 1 \rrbracket \geq 1.50 \mathrm{mmol} / \mathrm{L}=2$

Serum ferritin

100ug/L-500ug/L=0,ه100ug/L=18区500ug/L=2

PTH

150ug/L-600ng/L=0,ه150ng/L=1هष600ng/L=2

Taking all these factors into univariate Cox analysis,the results showed that gender,male patients with age under 60 years old,primary disease,total Ccr,PET,serum albumin and serum calcium had statistically significant effects on the technical survival rate of CAPD patients. Subsequently,these factors and other variables which are considered clinically relevant according to the current literaturewere were introduced into the Cox regression model for multi-factor analysis.

Table 6 Patient technique survival by Univariate and Multivariate Cox Proportional Hazards Analysis 
Variable

Univariate

$\begin{array}{llllll}\text { HR } & 95.0 \% \mathrm{Cl} & \mathrm{P} & \mathrm{HR} & 95.0 \% & \mathrm{P}\end{array}$
Age at the time of

dialysis initiation

Gender

Male patients with age under 60 years old

Primary disease

Degree of education

primary or

1.151

0.773
1.716

male

female

chronic

glomerulonephrit

hypertension

1.268

$0.700-$

2.298

0.434

$0.420-$

0.929

$0.020^{*}$

0.736

$0.417-\quad 0.289$

1.298

0.607

$0.406-$
0.909

$0.015^{*}$

0.633

$0.418-$

0.960

$0.031^{*}$

obstructive

nephropathy

systemic lupus

erythematosus

diabetes

others

1.072

$0.454-$

2.532

0.874

0.076

0.076

0.917

1.059

3.113

$0.030^{\star}$

1.212

0.375
2.584

0.974

0.987

8.099

0.053

2.331

1.816

0.618

2.088

0.682

0.971

2.060

1 middle school

high school

university and

above

illiteracy

Region

suburb
urban
other

suburban
0.592-

2.481

$0.458-$

0.534- 0.999

1.877

0.599

0.940
$0.622 \quad 0.363-\quad 0.084$

1.066

0.779

1.827

0.883

0.374
2.330

1

$0.932 \quad 0.616-\quad 0.737$

1.409

0.142

0.083
1.430

Payment method

urban workers'

1

insurance 


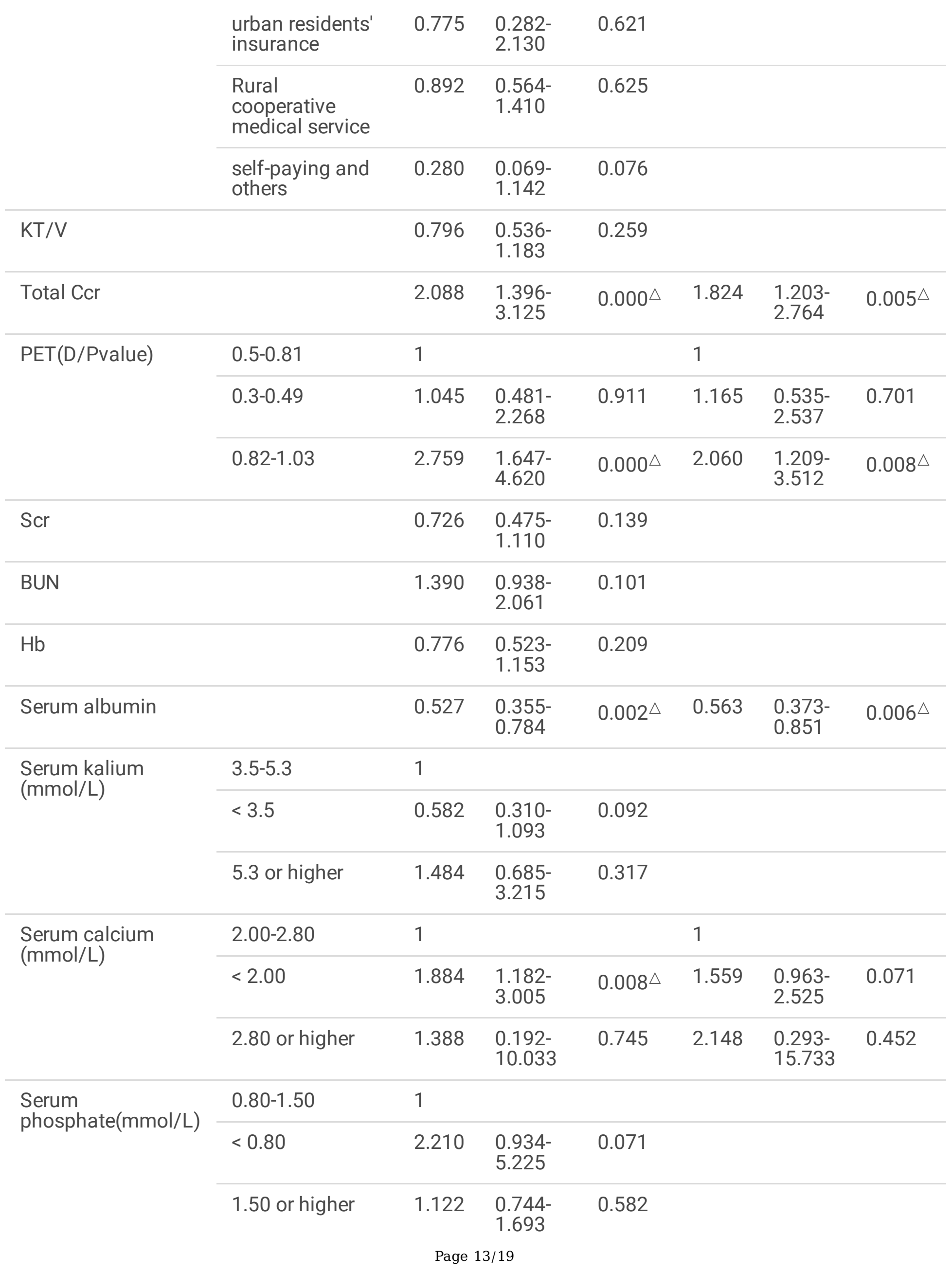


Serum ferritin

(ug/L)

\begin{tabular}{lllll} 
& $<100$ & 1.084 & $0.695-$ & 0.722 \\
& & & 1.690 & \\
\cline { 2 - 5 } & $>500$ & 1.375 & $0.764-$ & 0.288 \\
& & & 2.474 & \\
\hline PTH (ng/L) & $150-600$. & 1 & & \\
\cline { 2 - 5 } & $<150$ & 0.887 & $0.572-$ & 0.594 \\
& & & 1.377 & \\
\hline & & 0.575 & $0.314-$ & 0.073 \\
& & & 1.053 &
\end{tabular}

$\mathrm{HR}=1$ indicated the column was as a reference.

In the Cox proportional hazard model,patients' gender or age at PD initiation were not the risk factors of patient technique survival in our study. Nonetheless, male patients less than 60 years old had a 1.58 -fold higher risk of withdrawal than other patients. The withdrawal risk of patients with total Ccr above $60 \mathrm{~L} / \mathrm{W}$ was $82.4 \%$ higher than that of patients who did not meet the standard. The withdrawal risk of patients with high D/P Cr value which was calculated from PET were 2.06 times higher than those low-average and high-average patients. Additionally, patients with the data of serum albumin above $35 \mathrm{~g} / \mathrm{L}$ was easier to withdraw from PD than those people whose level of serum albumin was below $35 \mathrm{~g} / \mathrm{L}$.

\section{Discussion}

Peritoneal dialysis is a widely used method for end stage renal disease. There have been some literatures shown that the early life quality of CAPD patients is significantly better than that of hemodialysis patients in many aspects ${ }^{[6]}{ }^{[7]}$. Thus, exploring the correlations between sex, age and risk of technique survival might be helpful with the design of dialysis prescription for different clinical populations and prolonging the duration of sustainable treatment. There are different opinions about the effects of gender and age on the technical survival of PD patients. Chidambaram $\mathrm{M}$ et al. ${ }^{[8]}$ considered that aging was an important factor affecting the survival of patients. A single-center study done in South Korea ${ }^{[9]}$ demonstrated that young age was a significant independent factor associated with long term PD maintenance, but gender was not. Zhang $\mathrm{F}$ et al. ${ }^{[10]}$ studied the survival of $421 \mathrm{PD}$ patients and found that the survival of patients

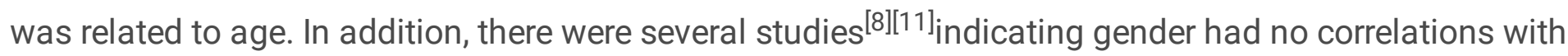
technology failure. Kitterera $\mathrm{D}^{[12]}{ }^{1}$ in the study of 745 patients with peritoneal dialysis failure and the relationship between gender found that the technical survival rate of female was significantly higher than

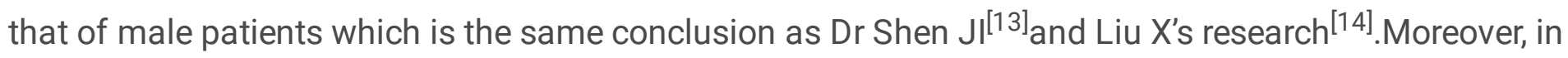
the analysis of risk factors related to outcomes of peritoneal dialysis patients from Taiwan, Chen $\mathrm{HL}^{[15]}$ also found the risk of technical failure of female patients was significantly lower when evaluating 
the clinical treatment effect on PD patients. In our retrospective analysis, the results of multi-factor COX regression analysis showed that gender or age at PD initiation (60 years old as the boundary) were not relevant risk factors for CAPD patients to withdraw, while male patients under 60 years old had a 1.58fold higher risk of withdrawal from PD than other patients.

The results of our study also suggested the total creatinine clearance rate and blood creatinine of male patients younger than 60 years old were higher than those of females at any age, furthermore the withdrawal risk of patients with total $\mathrm{Ccr}$ above $60 \mathrm{~L} / \mathrm{W}$ was $82.4 \%$ higher than patients who did not meet the standard. In the study on the relationship between serum creatinine and gender in healthy people, Cao Dan et al. ${ }^{[16]}$ found that the level of serum creatinine of men was higher than that of women in the same age. Besides, in the study on the relationship between serum creatinine and gender in peritoneal dialysis patients, Zhao Huanjia ${ }^{[17]}$ found that age, gender and BMI were independent factors affecting the level of serum creatinine. The level of serum creatinine was decreasing with the increasing of age, of which male patients were higher than that of female patients. This finding was consistent with our study of relationship between gender and the serum creatinine, and the reasons underlying the result might be multifactorial, in brief, the serum creatinine concentration mainly depends on muscle creatine phosphate decomposing and kidney producing. Our retrospective study suggested that the level of serum creatinine of male patients less than 60 years old was significantly higher than that of female patients at any age, and the ability to remove creatinine was significantly better than that of female patients. While the risk of withdrawal from PD was $82.4 \%$ higher than that of other patients whose total creatinine clearance rate did not reach $60 \mathrm{~L} / \mathrm{W}$, in the case that the clearance rate of residual renal creatinine was equal. Considering that previous dialysis guidelines suggested that KT/V should be no less than 1.7 and $\mathrm{Ccr}$ should be more than $60 \mathrm{~L} / 1.73 \mathrm{~m}^{2[5]}$, we held the opinion that $\mathrm{Ccr}$ reaching $60 \mathrm{~L} / 1.73 \mathrm{~m}^{2}$ was not clinically appropriate as an evaluation index of dialysis adequacy in male patients under 60 years old.

In our study, the multivariate Cox proportional hazards model showed that the level of serum albumin was a relevant risk factor for CAPD patients to withdraw from treatment. Chen $\mathrm{HL}^{[15]}$, Griva $\mathrm{K}^{[18]}$, Wang $\mathrm{J}^{[19]}$,et al. found that lower serum albumin levels were associated with an increased risk of technical failure in analysis of risk factors related to PD patients. The results of our analysis showed that the withdrawal risk of patients with serum albumin above $35 \mathrm{~g} / \mathrm{L}$ was $43.7 \%$ lower than that of patients below $35 \mathrm{~g} / \mathrm{L}$. Although there was no statistically significant difference in serum albumin between male and female patients when compared by gender as a whole, the level of serum albumin of male patients under 60 years old was significantly higher than that of male patients over 60 years old. It was suggested that nutritional issues, namely albumin levels, was not the reason why men younger than 60 years old withdrawl from peritoneal dialysis.

In addition, our study demonstrated peritoneal transport characteristics were the relevant factors affecting the technical survival of CAPD patients. The withdrawal risk of patients with high value of $D / P$ $\mathrm{Cr}$ of peritoneal equilibrium test (PET) were 2.06 times higher than those low-average and high-average patients, while patients with low transport of PET had no statistical differences in the risk of dropping out. 
Just as $\mathrm{Li} \mathrm{Han}^{[20]}$ believed that the Ccr of patients with low transport were not easy to reach $60 \mathrm{~L} / 1.73 \mathrm{~m}^{2}$, while its technical survival rate were not low but even exceed that of patients with high transport. A study from Japan ${ }^{[21]}$ also demonstrated the value of high $\mathrm{P} / \mathrm{D} \mathrm{Cr}$ was also associated closely with higher mortality and failure of peritoneal dialysis. Our study compared different gender groups which suggested that the values of $P / D$ Cr of male patients were higher than that of female patients on average, which was consistent with the findings found by Lin tao ${ }^{[22]}$ that male gender was a risk factor for high peritoneal transport status. In addition, our study also suggested KT/V of male patients were significantly lower than female patients at any age. It told us that men had disadvantages over women in peritoneal transport characteristics and urea scavenging index. Especially for male patients younger than 60 years old, we speculated the reason why such patients were more likely to withdraw from peritoneal dialysis was related to their high peritoneal transport characteristics and insufficient clearance of small molecules of CAPD. In the future, automated peritoneal dialysis (APD) could be further observed to explore the survival rate of peritoneal dialysis in male patients younger than 60 years old.

There were still some limitations in our study. The retrospective analysis of single-center small sample size limited the investigation and information collection of the whole peritoneal dialysis population. Besides, no suitable indicators for the evaluation of peritoneal sufficiency in male patients younger than 60 years old had been found. Therefore it is necessary to further explore the reasons for easily withdrawal of male patients who are younger than 60 years old and design a more appropriate prescription for peritoneal dialysis patients to improve their technique survival rate.

\section{Conclusions}

In summary,the study implied that patients with high D/Pcr value or with serum albumin under $35 \mathrm{~g} / \mathrm{L}$ were related risk factors for technique survival,and male patients who are under 60 years old had a higher risk of withdrawal from PD.The outcome also suggested that Ccr above 60L/W was not suitable as an index for evaluating the adequacy of PD,especially for men under 60 years old.

\section{Abbreviations}

BUN:Blood Urea nitrogen;CKD:Chronic kidney disease;Cr:Creatinine;Ccr:Creatinine clearance rate;CAPD:Continuous ambulatory peritoneal dialysis;DM:Diabetes mellitus;ESRD:End-stage renal disease;HD:Hemodialysis;Hb:Hemoglobin;HR:Hazard ratios;KT/V:Urea clearance index;PD:Peritoneal dialysis;PET:Peritoneal equilibration test;PTH:Parathyroid hormone;Scr:Serum creatinine

\section{Declarations}

\section{Acknowledgments}


The authors thank all of members in the PD center of Wuhan NO-1 Hospital for their careful management of PD patients constantly and for their help in conducting this study.

\section{Authors'Contributions}

ZYM and HM contribute equally to the manuscript.ZYM and XF conceived and designed the study.HM,WS,DYQ collected the data.HM and LL analyzed the data,ZYM and HM prepared tables and figures,and wrote the manuscript.HYL polished the article with the translation.All authors read and approved the final manuscript.

\section{Funding}

None.

\section{Availability of data and materials}

The data supporting the findings of this study were used under license for the current study and are not publicly available.However,with a reasonable request,the author can provide the data.

\section{Ethics approval and consent to participate}

This study was approved by the Wuhan No.1 Hospital Ethics Committee Review Board and written informed consent was exempt due to its retrospective nature.

\section{Consent for publication}

Not applicable.

\section{Competing interests}

The authors declare that they have no competing interests. 


\section{References}

1. Jha V, Garcia-Garcia G, Iseki K,et al. Chronic kidney diease: global dimensionand perspectives [. J]Lancet. 2013;382(9888):260-72.

2. Zhang L, Wang F, Wang L,et al.Prevalence of chronic kidney disease in Chana: a cross-sectional survey [J].Lancet,2012,380(9838):815-822.

3. Vasudevan A,Phadke K,Yap HK.Peritoneal dialysis for the management of pediatric patients with acute kidney injury [J].Pediatr Nephrol,2017,32(7):1145-1156.

4. Levey AS, De Jong PE, Coresh J,et al.The definition,classification and prognosis of chronic kidney disease:a KDIGO Controversies Conferencereport [J].Kidney Int,2011,80(1) :17-28.

5. Chen XM, Ni ZH, Yuan WJ,et al.Peritoneal Dialysis Standard Operating Procedure(SOP)[M].Beijing: PEOPLE'S MILITARY MEDICAL PRESS,2010:160-163.

6. Ma ZD, Zheng ZH, Zhang DH,et,al.Multi-center investigation of quality of life in hemodialysis and peritoneal dialysis patients [J].Chinese Journal Of Nephrology,2004,20(6):400-405.

7. Chen JY, Wan EYF, Choi EPH,et al.The Health-Related Quality of Life of Chinese Patients on Hemodialysis and Peritoneal Dialysis [J].Patient,2017,10(6):799-808.

8. Chidambaram M, Bargman JM, Quinn RR,et al. Patient and physician predictors of peritoneal dialysis technique failure: A population based, retrospective cohort study [J]. Perit Dial Int. 2011;31(1):56573.

9. Kee YK, Park JT, Kim H,et al.Characteristics and Clinical Outcomes of End-Stage Renal Disease Patients on Peritoneal Dialysisfor Over 15 Years:A Single-Center Experience [J] .Perit Dial Int,2017,37(5):535-541.

10. Zhang F, Liu H, Gong X. et al.Risk factors for mortality in Chinese patients on continous ambulatory peritoneal dialysis [J]. Perit Dial Int. 2013;35(2):199-205.

11. Han SH, Lee JE, Kim DK,et al.Long term clinical outcomes of peritoneal dialysis patients: Single center experience from korea [J]. Perit Dial Int,2008,28(3):21-26.

12. Kitterera D, Segererb S, Braunc N,et al.Gender-Specific Differences in Peritoneal Dialysis[J].Kidney Blood Press Res,2017,42:276-283.

13. Shen JI, Mitani AA, Saxena AB,et al. Determinants of peritoneal dialysis technique failure in incident us patients [J]. Perit Dial Int. 2013;33(2):155-66.

14. Liu $X$, Huang $\mathrm{R}$, Wu H,et al.Patient characteristics and risk factors of early and late death in incident peritoneal dialysis patients [J].Nature Scientific Reports,2016,6(32359): 1-8.

15. Chen HL, Tarng DC, Huang $L H$,et al. Risk factors associated with outcomes of peritoneal dialysis in Taiwan An analysis using a competing risk model [. J]Medicine. 2019;98(6):1-8.

16. CAO, D,ZHANG WG,ZHANG, YP,et al.The physiological range of renal filtration function index and its influencing factors in healthy people of different ages [J].Chinese Journal of Integrated Traditional and Western Nephrology,2017,18(5): 409-411. 
17. Zhao HJ, Tian XK, Chen BJ,et al.Factors affecting the levels of serum creatininein continuous ambulatory peritoneal dialysis patients[J].Chinese Journal of Integrated Traditional and Western Nephrology,2011,12(2): 119-121.

18. Griva K, Kang AW, Yu ZL, et al. Predicting technique and patient survival over 12 months in peritoneal dialysis: the role of anxiety and depression [J]. Int Urol Nephrol,2016,48(5):791-6.

19. Wang J, Xie X,Yan X,et al. A Fast Decline of Residual Renal Function in the First Year is a Predictor for Early Withdrawal from Peritoneal Dialysis in Non-Diabetic Patients [J]. Kidney Blood Press Res. 2019;44:12-21.

20. Li H,Wang SX.The status of evaluation indexes of peritoneal dialysis adequacy [J].International Journal of Transplantation and Hemopurification,2006,4(3): 8-11.

21. Sun T, Sakata F, Ishii T,et al. Excessive salt intake increases peritoneal solute transport rate via local tonicity-responsive enhancer binding protein in subtotal nephrectomized mice [J]. Nephrol Dial Transplant. 2019;5:1-12.

22. Lin T, Yu GP, Xie JY,et al.Risk factors analysis of initial high peritoneal solute transport status in peritoneal dialysis patients[J].Journal of Shanghai Jiao Tong University (Medical Science),201737(8): 1090-1093. 